\title{
Estados da Periferia são frágeis? Breve análise do BRICS ${ }^{1}$
}

\author{
Periphery states are fragile? Brief analysis of the BRICS
}

\section{Claudia Santos ${ }^{2}$}

\section{Resumo}

Esta discussão foi baseada à priori no livro de Milton Santos Por uma outra globalização (2000) e o documentário Encontro com Milton Santos: o mundo global visto do lado de cá (2006), tendo como objetivo central oferecer uma perspectiva de argumentação e reflexão que se opõe às concepções de Milton Santos por meio de outras perspectivas à fragilidade dos Estados periféricos no processo de globalização. Analisa-se o caso dos BRICS em suas políticas fiscais nas dinâmicas econômicas internacionais nos últimos anos.

Palavras-Chave: Globalização; BRICS; Milton Santos.

\begin{abstract}
This discussion was based on a priori book of Milton Santos On another globalization (2000) and the documentary Encontro com Milton Santos: o mundo global visto do lado de cá (2006) having as its central objective to offer a perspective of reflection and argumentation opposed to conceptions of Milton Santos through other perspectives to the fragility of peripheral states in the process globalization. Analyzes the case of BRICS in their fiscal policies in international economic dynamics in recent years.
\end{abstract}

Keywords: Globalization; BRICS; Milton Santos.

No final dos anos 1990, o geógrafo Milton Santos (1926-2001), preocupado com os processos transnacionais das empresas e do capital publicou sua obra Por uma outra globalização (2000). Na presente obra, desdobrada em um documentário Encontro com Milton Santos: o mundo global visto do lado de cá (Silvio Tendler, 2006), a ideia de que existiria uma desregulação da produção e exploração empresarial internacional foi defendida. Dentro desse cenário descrito por Santos (2000), países periféricos, como o Brasil e toda a América Latina, estariam vulneráveis ao terem adotado o modelo

\footnotetext{
${ }^{1}$ Artigo recebido em 20 de março de 2014 e aprovado em 31 de março de 2014.

${ }^{2}$ Graduanda em Relações Internacionais pelo Centro Universitário Internacional - UNINTER, Curitiba, Brasil.
}

Conjuntura Global, Vol.3, n.1, jan./mar., 2014, p. 56-64. 
econômico neoliberal dos anos 1980 e 1990. Essa adoção, seguindo o Consenso de Washington ${ }^{3}$, teria enfraquecido os Estados periféricos diante dos fluxos econômicos da globalização.

Os fluxos econômicos da globalização presenciados por Milton Santos diz respeito à percepção de que existira um certo número de empresas, sediadas em Estados desenvolvidos - centrais - que explorariam os recursos de produção de Estados em desenvolvimento ou subdesenvolvidos sem grandes responsabilidades com as populações locais. Apesar de não se considerar um marxista ortodoxo (TENDLER, 2006), Milton Santos baseou seus estudos e o discurso resultante da obra (2000) nas ideias marxistas de organização social e nas dinâmicas das relações estatais e empresariais. Estados em desenvolvimento, ao aderirem o neoliberalismo estariam se fragilizando diante das grandes empresas transnacionais e, consequentemente, dos Estados que centralizariam as riquezas de produção global. Na fala do Ministro de Relações Exteriores Celso Amorin (TENDLER, 2006), os Estados estariam mais fortes do que nunca, e essa desregulação econômica defendida aos Estados latino-americanos não condiz com o caminho de fortalecimento dos Estados Unidos e Europa.

Para o autor, "notícias são interpretações de fatos, por isso são analisadas dependendo da área de interesse" e, portanto, existiria uma divisão entre o agir dos países ricos e o pensar em orientação aos países em desenvolvimento. Essa frase expressa, com certa relação, o discurso terceiro-mundista presente ao longo da obra de Milton Santos (2000). A partir de seu ponto de vista, a globalização, portanto, seria um processo de influências, direta ou indiretamente, que possuiria efeito perverso sobre a humanidade, decorrentes desde o imperialismo desenfreado dos países hegemônicos mundiais até a má utilização do desenvolvimento tecnológico atual. Em seu discurso em Paris, nos anos 1990, registrado no documentário de Silvio Tandler (2006), Milton Santos defende que o grande desafio no atual mundo globalizado não seriam os recursos - contrariando a percepção malthusiana - mas o uso correto da tecnologia para diminuir

\footnotetext{
3“'O Consenso de Washington foi a forma como ficou popularmente reconhecido um encontro ocorrido em 1989, na capital dos Estados Unidos. Nesse encontro, realizou-se uma série de recomendações visando ao desenvolvimento e à ampliação do neoliberalismo nos países da América Latina. Essa reunião foi convocada pelo Institute for InternationalEconomics, sob o nome de "Latin Americ Adjustment: Howe Muchhas Happened?" ", e envolveu instituições e economistas de perfil neoliberal, além de alguns pensadores e administradores de países latino-americanos". Disponível em: http://www.brasilescola.com/geografia/consensowashington.htm. Acesso em 08 de mar. 2014.
}

Conjuntura Global, Vol.3, n.1, jan./mar., 2014, p. 56-64. 
a fome e as desigualdades sociais. Porém, para o geógrafo, esse desafio se agravaria poisas grandes empresas e seus Estados centrais não desistiriam das atuais dinâmicas de ganhos.

Para Milton Santos (2000), a oportunidade de mudar o mundo ou um país, está na Política, pois nela reside a possibilidade de se criar melhores expectativas e colocá-las em prática. Ele propõe que a globalização, de forma normativa, fosse horizontalizada e não vertical como a percebia. Dessa forma, com Estados fortes e maior participação de agentes sociais e novos atores, o processo de globalização direcionaria o uso da tecnologia para diminuição das desigualdades provocadas pelo uso indevido das mesmas, somado ao neoliberalismo que teria enfraquecido os Estados em desenvolvimento - ou periféricos. Para o autor (2000) aglobalização contemporânea se caracteriza por sua perversidade por conta da desvalorização do trabalhador, diminuição de salário e um aumento crescente de desempregos, contrapondo os princípios de igualdade, o que reafirma a posição elitista imposta pelo capitalismo e a opressão da outra parte.

Nas relações internacionais o marxismo representa uma teoria alternativa e que não se coloca ao centro das teorias tradicionais como o realismo e o liberalismo, mas contribuindo, de modo paralelo, nos questionamentos mais específicos referentes aos temas como desigualdade e status quo internacional. Na tese marxista de Infraestrutura (meios de produção) e Superestrutura (direito, cultura, etc.), os Estados reproduziriam o seu modelo de dominação vigente por meio da superestrutura, sendo a política externa voltada para os interesses dominantes existentes dentro do país.

O Estado deste ponto de vista não procura o bem-estar coletivo, mas apenas de uma minoria, sendo o Estado o principal mantenedor da força, para Marx o discurso de bem comum e justiça é apenas uma ideologia utilizada como estratégia pelos atores da superestrutura que legitimam seu próprio poder. A guerra é vista como uma consequência natural do modelo econômico capitalista tornandodeste modo, o conflito sempre presente nas relações internacionais em função do modo de produção capitalista e da luta de classes.

Conjuntura Global, Vol.3, n.1, jan./mar., 2014, p. 56-64. 


\section{BRICS e Globalização}

Depois desta breve introdução do pensamento marxista que orienta Milton Santos no seu trabalho diante da globalização, o objetivo agora se orienta em desdobraro que este autor apresenta diante do atual cenário de alguns Estados historicamente tidos como periféricos ${ }^{4}$ no caso dos BRICS. Primeiramente deve-se apresentar quem são os BRICS. Formados por Brasil, Rússia, Índia, China e África do Sul, os BRICS representam o crescimento dos mercados emergentes e potenciais agentes do crescimento global. Em uma perspectiva econômica à globalização, esses cinco Estados tratados historicamente como segundo-mundistas (Rússia e China) e terceiro-mundistas (Brasil, Índia e África do Sul) alcançaram, ainda que dentro de uma possível periferia marxista, um posicionamento de destaque e crescimento ${ }^{5}$. Ainda que existam grandes desafios sociais, a realidade no Brasil, segundo o IPEA $^{6}$, tem melhorado significativamente.

Ao utilizar-se dos termos "vulnerabilidade" e "sensibilidade"7, na perspectiva mais liberal de Robert Keohane (1998), o grande problema apontado por analistas internacionais quanto a uma possível fragilidade econômica do BRICS como economias emergentes e sua vulnerabilidade às políticas monetáriasdos países centrais, como a norte-americana, reside em alguns dados levantados pelo relatório semestral de política monetária do Federal Reserve (FED), onde o banco central dos EUA“sustentou que o Brasil é a segunda economia emergente mais vulnerável às alterações recentes do

\footnotetext{
4

${ }^{5}$ Segundo o Instituto de Pesquisas Econômicas Aplicadas (IPEA), os membros do BRICS ainda que com desafios em alguns setores de desigualdade social vem progredindo em um cenário macro, sobretudo o Brasil. Disponível em: http://www.ipea.gov.br/portal/index.php?option=com content\&view=article\&id=21884\&catid=6\&Itemid=4. Acesso em 29 de mar. 2014.

${ }^{6}$ Disponível em: http://www.ipea.gov.br/portal/index.php?option=com_content\&view=article\&id=21884\&catid=6\&Itemid=4. Acesso em 29 de mar. 2014.

7“"Para Keohane as duas dimensões nas quais a interdependência pode ser trabalhada são a sensibilidade e a vulnerabilidade. A sensibilidade é pertinente as influências internas sociopolíticas, em que a ação de um ator " $X$ " provoca efeitos no ator "Y". A sensibilidade então é a capacidade de se ajustar para reverter os efeitos de uma ação tomada por ouro ator.A vulnerabilidade revela a fragilidade de um ator, que mesmo após ter tomado medidas protecionistas continuam sujeitos aos efeitos das ações tomadas pelo outro ator, podendo às vezes motivar a tomada de decisões bruscas na tentativa de reverter a situação”. FREIRE, Antonio. O neoliberalismo e a teoria da interdependência complexa. Disponível em: http://www.jurisway.org.br/v2/dhall.asp?id_dh=7410. Acesso em 08 de mar. 2014. Obra utilizada: .Keohane Robert and Joseph Nye,PowerandInterdependence in theInformation Age: Foreign Affairs, Vol. 77, No. 5 (Sep. - Oct., 1998), pp. 81-94.
}

Conjuntura Global, Vol.3, n.1, jan./mar., 2014, p. 56-64. 
cenário internacional" (CURADO, 2014). Segundo essa percepção mais crítica diante da vulnerabilidade dos BRICS pode ser vista a seguinte imagem:

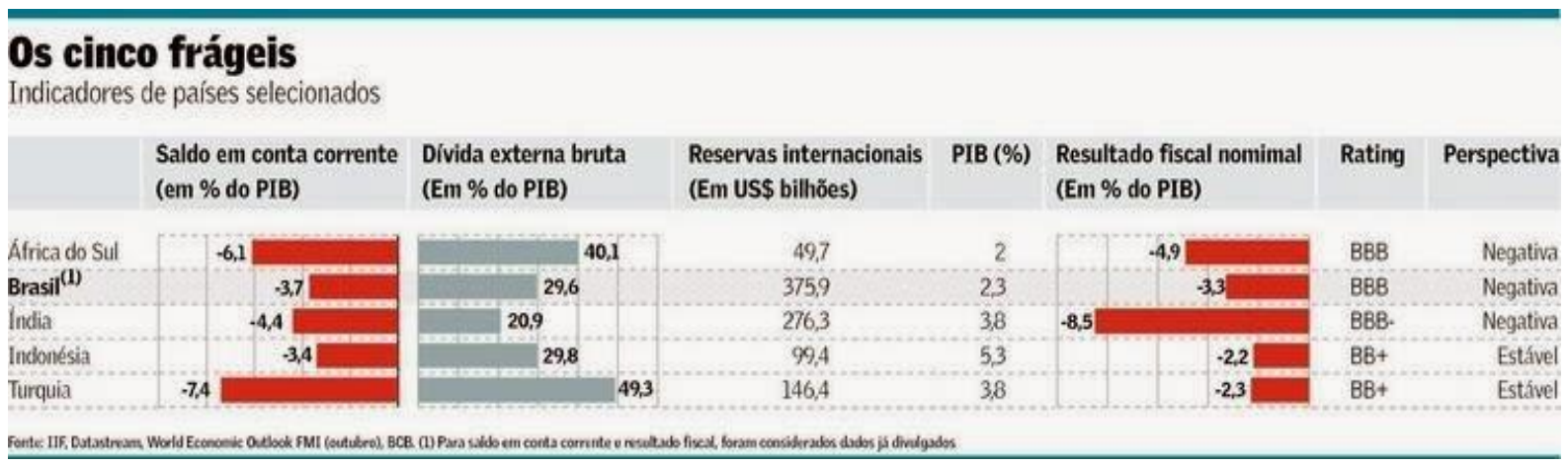

Os cinco frágeis: BRICS e a vulnerabilidade econômica. Fonte: IIF, Datastream, World Economic Outlook FMI (outubro), BCB, (1) para saldo em conta corrente e resultado fiscal, foram considerados dados já divulgados. Acesso em 08 de mar. de 2014.

Segundo Oliveira (2011), seu pensamento vai de encontro com a perspectiva marxista de que "esse sistema montado para dar suporte ao crescimento, não consegue atender às demandas econômicas e sociais" (OLIVEIRA, 2011). E assim o argumento marxista de que o crescimento econômico na periferia estaria sempre condicionado às políticas econômicas dos países centrais. Porém, do ponto de vista neoliberal, retomando para além dos critérios de vulnerabilidade e fragilidade, as economias desses países buscam, com as reuniões anuais do grupo, ampliar uma interdependência fortalecendo-se diante do cenário internacional e mostrando possíveis caminhos à nãodependência marxista como fato ontológico das relações internacionais. Para tanto, o BRICS, apesar de fragilidades individuais, pode fortalecer-se, em um nível mais normativo de análise, diante das políticas monetárias e empresariais de Estados e empresas tidos como centro do mundo.

Um dado empírico que pode sustentar essa opção de relacionar-se para além das dinâmicas de uma determinada dependência marxistas encontra-se no aumento das relações comerciais entre os integrantes do BRICS. O Brasil, por exemplo, é um dos maiores exportadores de grãos para a China, sendo a China o terceiro maior Estado investidor internacional ${ }^{8}$ e detentores da dívida externa norte-americana ${ }^{9}$ (1,3 trilhão

\footnotetext{
${ }^{8}$ Disponível em: http://www.inovaportugal.com/china-e-terceiro-maior-investidor-a-nivel-mundial/. Acesso em 08 de mar. 2014.

9 Disponível em: http://exame.abril.com.br/economia/noticias/china-possui-us-1-3-trilhao-de-divida-dos-eua. Acesso em 03 de mar. 2014
}

Conjuntura Global, Vol.3, n.1, jan./mar., 2014, p. 56-64. 
de dólares). Enquanto isso, a população dos integrantes do BRICS superam a população dos países tidos como centrais - Estados Unidos e União Europeia, por exemplo. Esse dado altera a relação ontológica marxista de dependência, pois cria um mercado de produção e consumo muito maior do que o centro pode atender, forçando Brasil, Rússia, Índia China e África do Sul a ampliarem suas produções e serviços, bem como ter maior peso nas negociações internacionais ao atuar em bloco.

Analisando desta vez o viés político do BRICS pela perspectiva marxista, os países periféricos são aqueles que sobre a influência dos países hegemônicos influenciam os demais países do seu continente, sobre os quais também possuem determinada influência. Em um artigo Lima (2012), se pergunta "há coesão interna para que os BRICS atuem concentradamente e acelerem as transformações na grande política mundial?" e sua resposta é:

A coesão interna ainda é muito frágil, até por ser nova. Trata-se de países que, se tinham alguma relação entre si, elas se davam de modo bilateral. Há tensões geopolíticas fortes, a exemplo da China e Índia, que têm uma forte tradição de serem adversários. Do ponto de vista geopolítico, o Brasil talvez seja o país melhor (LIMA, 2012).

A política externa brasileira se pauta no princípio de resolução pacífica de conflitos e negociações diplomáticas. Por muitos autores o Brasil - e diga se de passagem, também para os Estados Unidos - o Brasil é reconhecido como um líder na América do Sul ${ }^{10}$, ainda que muitas comunidades e Estados da região não o percebam como tal. Mas de toda a forma o Brasil desde a Liga das Nações vem se projetando no cenário internacional como Global Player e almeja um assento no Conselho de Segurança possivelmente como um auto reconhecimento de seu papel. Assim os demais membros do BRICS também buscam reconhecimento internacional e ao nível regional, como a Rússia em relação às antigas repúblicas soviéticas ${ }^{11}$, Índia e África do Sul em suas

\footnotetext{
${ }^{10}$ Disponpivel em: http://www.fride.org/descarga/COM_Brazil_Sudamerican_ENG.pdf. Acesso em 08 de mar. 2014.

11 Disponível em: http://www.cartacapital.com.br/internacional/ex-republicas-sovieticas-na-mira-de-moscou7403.html. Acesso 08 de mar. 2014
}

Conjuntura Global, Vol.3, n.1, jan./mar., 2014, p. 56-64. 
regiões e a China no mercado internacional e financiamentos significativos no continente africano - aproximadamente 75 bilhões de dólares ${ }^{12}$.

\section{Considerações Finais}

Se existem fragilidades e sensibilidades diante de Estados centrais, os integrantes do BRICS, buscam construir relações que diminuam essa relação de dependência e, portanto, ao mínimo questionam a ontologia dependentista do marxismo aplicado às relações internacionais. Fonseca Júnior (2012) e Leão (2012) também analisam essa relação de fragilidade e sensibilidade sob um ponto de vista neoliberal que,ao mínimo, também questionam a percepção ontológica da dependência marxista nas relações internacionais através da heterogeneidade nas agendas dos integrantes do bloco. Visentini (2012), que também analisa as dinâmicas internacionais envolvendo os membros do BRICS, alerta que, em casos como o da China, os Estados tidos como fora do centro de poder internacional na percepção marxista, não enfraqueceram como levantado por Celso Amorim anteriormente (TANDLER, 2006), bastando apenas olhar para a China que, ao contrário, possui um alto nível de governabilidade doméstica e estrutura mais resistente às crises internacionais.

A impossibilidade aparente de concordância entre os membros dos BRICS sobre temas vitais ao mesmo tempo quefragilizamtambém fortalecem o bloco. Como não há a perspectiva de ação conjunta sobre nada que de fato interesse, os países têm mais liberdade para dialogar e para argumentar em teoria e, assim, exercer influência ideológica internacional (SILVA, 2012).

A conclusão que se pode chegar com esta pesquisa é que há sim pontos fracos nos BRICS, como mostrados na pesquisa, mas também pontos positivos como aponta Lopes em sua resenha (2011), de que houve nestes países uma política de inovação que "possibilitou, segundo os autores, a formulação explícita do conceito de sistema nacional de inovação nos projetos de incentivo à expansão da ciência e tecnologia" (LOPES,

\footnotetext{
${ }^{12}$ Disponível em: http://www.bbc.co.uk/portuguese/noticias/2013/04/130430_china_africa_ru.shtml. Acesso em 08 de mar. 2014.
}

Conjuntura Global, Vol.3, n.1, jan./mar., 2014, p. 56-64. 
2011). Pode-se dizer que essa troca de experiências, e costumes, por meio de negociações, contatos o que na antropologia se denomina como "aculturação" e que acontecem inevitavelmente nestes países é um acréscimo para os processos de cooperação internacional e porque não de governança. Os novos caminhos à ontologia marxista da dependência questiona alguns argumentos levantados por Milton Santos quanto ao enfraquecimento de Estados não-centrais.

Essa, por sua vez, pressupõe novos atores como os blocos dos países emergentes, empresas transnacionais, organizações não governamentais internacionais, redes e fóruns globais que caracterizam um multilateralismo complexo que requer novos processos de participação, negociação e tomada de decisão a cerca de questões e desafios globais à humanidade, como temas desde segurança internacional, questões ambientais até direitos humanos e que demandam a superação das incertezas e assimetrias que dificultam a cooperação entre os atores internacionais, principalmente entre os novos atores com os blocos dos países emergentes, suas empresas transnacionais, organizações não-governamentais, redes e os fóruns globais. Assim, um novo questionamento inicia-se: qual o papel dos BRICS na governança global? Por hora limita-se a percebê-los como vetores de novas possibilidades frente à globalização abordada por Milton Santos.

\section{REFERENCIAS}

CURADO, Marcelo. Brasil: Bric ou membro dos "Cinco Frágeis"?. 2014. Disponível em: <http://www.gazetadopovo.com.br/opiniao/conteudo.phtml?id=1450814 >. Acesso em: 08 mar. 2014.

FONSECA JR. Gelson. BRICS: notas e questões. FUNAG. 2012. Disponível em: < http://www.funag.gov.br/biblioteca/dmdocuments/OBrasileosBrics.pdf\#page=67>. Acesso em: 08 mar. 2014.

LEÃO. Valdemar Carneiro. BRICS: identidade e agenda econômica. FUNAG. 2012. Disponível em: 
<http://www.funag.gov.br/biblioteca/dmdocuments/OBrasileosBrics.pdf\#page=67>. Acesso em: 08 mar. 2014.

LIMA, Marcos Costa. O Brasil, os BRICS e a agenda internacional. FUNAG. 2012. Disponível em: <http://www.funag.gov.br/biblioteca/dmdocuments/OBrasileosBrics.pdf\#page=67>. Acesso em: 08 mar. 2014.

LOPES, Tiago Camarinha. Resenha de BRICS and development alternatives: innovation systems and policies. Economia Ensaios, v. 25, n. 2, 2011. <http://www.seer.ufu.br/index.php/revistaeconomiaensaios/article/viewFile/22471/ 12256 >. Acesso em: 08 mar. 2014.

MOTA, Ronaldo. 0 Brasil, os BRICS e o cenário de inovação. FUNAG. 2012. Disponível em:

http://www.funag.gov.br/biblioteca/dmdocuments/OBrasileosBrics.pdf\#page=67> . Acesso em: 08 mar. 2014.

NOGUEIRA, J. P.; MESSARI, N. Teoria das Relações Internacionais. São Paulo: Campus, 2005.

OLIVEIRA, Regiane de. Educação é o elo frágil dos países do grupo Brics. 2011. Disponível em: < http://brasileconomico.ig.com.br/noticias/educacao-e-o-elo-fragildos-paises-do-grupo-brics_109074.html >. Acesso em: 08 mar. 2014.

SANTOS, Milton. Por Uma Outra Globalização: Do pensamento único a consciência universal. Editora Record, 2000.

SILVA, Carlos Eduardo Lins da. BRICS: De acrônimo esperto a fórum influente. FUNAG. 2012. Disponível em:

http://www.funag.gov.br/biblioteca/dmdocuments/OBrasileosBrics.pdf\#page=67>. Acesso em: 08 mar. 2014.

VISENTINI. Paulo Fagundes. A dimensão político-estratégica dos BRICS: entre a panaceia e o ceticismo. FUNAG. 2012. Disponível em: < http://www.funag.gov.br/biblioteca/dmdocuments/OBrasileosBrics.pdf\#page=67>. Acesso em: 08 mar. 2014.

Conjuntura Global, Vol.3, n.1, jan./mar., 2014, p. 56-64. 